\title{
Efficacy of black cohosh (Cimicifuga racemosa L.) in treating early symptoms of menopause: a randomized clinical trial
}

\author{
Sakineh Mohammad-Alizadeh-Charandabi, Mahnaz Shahnazi, Jila Nahaee* and Somaei Bayatipayan
}

\begin{abstract}
Background: This study aims to evaluate the efficacy of Black cohosh (Cimicifuga racemosa L.) in treating early menopausal symptoms.

Methods: This randomized, double-blind, placebo-controlled clinical trial was conducted on 84 early post-menopausal participants with Greene climacteric scale (GCS) scores of 15 to 42, who were referred to two public health care centers in Tehran, Iran, in 2011-2012. The participants were randomly allocated into treatment (6.5 mg of dried extract of Black cohosh roots daily) and control (placebo) groups with a ratio of 1:1. The participants took one tablet per day for 8 weeks. The GCS scores were recorded at baseline, and after 4 and 8 weeks of treatment. Data analysis was carried out using a general linear model with repeated measures with SPSS software. The level of significance was set at $P<0.05$.

Results: There was no loss to follow-up during the 8 weeks of treatment. The GCS total score (primary outcome) in the treatment group was significantly lower than that in the control group at both week 4 [adjusted mean difference: -7.8 (95\% confidence interval: -11.1 to -4.4$)]$ and week 8 [-12.9 (-16.2 to -9.3$)]$. The treatment group showed significantly more improvement than the control group in all GCS subscale scores (vasomotor, psychiatric, physical, and sexual symptoms; secondary outcomes). The differences between the treatment and control groups at week 8 were significantly higher $(P<0.001)$ than those at week 4 in terms of the total scores and the vasomotor and psychiatric subscale scores. No side effects were reported.
\end{abstract}

Conclusions: Black cohosh reduced the GCS total score and all GCS subscale scores (vasomotor, psychiatric, physical, and sexual symptoms) during 4 and 8 weeks of treatment.

Clinical trial registration: This study was approved (Code 9061) by the Ethics Committee of Tabriz University of Medical Sciences and registered at the Iranian Registry of Clinical Trials with IRCT201107186709N4 on 15 January 2012.

\section{Background}

Menopause is the final menstrual period, and occurs at an average age of 51 years $[1,2]$. The number of peri-menopausal women is increasing in the world [1].

Menopause happens because of loss of ovarian activity, and is associated with a number of early and late symptoms. Early symptoms include hot flashes, insomnia, sweating, anxiety, palpitations, headaches, poor concentration, and loss of libido [3,4]. These symptoms usually last for 1 or 2 years after menopause, but may continue up to 10 years or more in some women [2]. The symptoms may reduce quality of life, and are independent of age and

\footnotetext{
* Correspondence: jnahaee@yahoo.com

Midwifery Department, Tabriz University of Medical Sciences, Tabriz, Iran
}

other sociodemographic variables [5]. In a study in Ilam, Iran, early post-menopausal women suffered vasomotor symptoms (55\%), vaginal dryness and decreased libido (43\%), and mild anxiety and depression (54\%) [6].

Hormone replacement therapy is the standard treatment for early symptoms in post-menopausal women [7], but increases the risks of stroke, heart diseases, and breast cancer in older women $[8,9]$. Some studies have shown that the number of post-menopausal women using hormone replacement therapy is low [10] and that the effects of hormone replacement therapy in reducing menopausal symptoms are lower than expected [11,12]. For these reasons, there has been a tendency toward use of alternative therapies to relieve menopausal symptoms $[13,14]$.

() Biomed Central

(c) 2013 Mohammad-Alizadeh-Charandabi et al.; licensee BioMed Central Ltd. This is an open access article distributed under the terms of the Creative Commons Attribution License (http://creativecommons.org/licenses/by/2.0), which permits unrestricted use, distribution, and reproduction in any medium, provided the original work is properly cited. 
Black cohosh (Cimicifuga racemosa L.) is an herb proposed for treatment of menopausal symptoms [15]. Cimicifuga roots and rhizomes contain triterpene glycosides (e.g., actein, 27-deoxyactein, and cimifugaside) and alkaloids (e.g., cytisine and N-methyl cytisine), derivatives of phenylpropane (e.g., ferulic acids and isoferulic acids), and cimicifugine (25-50\% of the root components) [15]. Although the exact mechanisms underlying the effects of Black cohosh have not been determined, its medical effects are related to triterpene glycosides [16]. It functions in a serotogenic manner rather than an estrogenic manner [17-19], binds to estrogen receptors, and selectively suppresses luteinizing hormone secretion with no effect on follicle-stimulating hormone [20].

The effects of Black cohosh on early menopausal symptoms have been inconsistent [21-25]. A systematic review [26] conducted on six randomized controlled trials (RCTs) with a total of 1163 peri- and post-menopausal women concluded that the efficacy of Black cohosh in reducing the symptoms was currently not supported by fully conclusive evidence, and that further investigations were desirable. Another review [27] of 16 studies that addressed the weaknesses of previous studies and their heterogeneity found insufficient evidence to support the efficacy of Black cohosh on early menopausal symptoms.

Black cohosh is well tolerated and is generally safe $[15,26,28,29]$. However, some insignificant side effects, such as nausea, vomiting, headaches, and dizziness were reported $[15,26]$. We found no data for toxic doses of Black cohosh. No serious side-event was reported even in a study [24] using a higher dose of Black cohosh that included $128 \mathrm{mg} /$ day standardized to $7.27 \mathrm{mg}$ of triterpene glycosides (ethanolic extract of Black cohosh).

The Greene climacteric scale (GCS), which is used to assess the symptoms of menopause, is a comprehensive validated tool consisting of 21 questions that women use to rate how much they are bothered by the symptoms [30].

The inconclusive evidence on the efficacy of Black cohosh has resulted in inconsistent practices by clinicians regarding the prescription of Black cohosh in the study area, leading to confusion for some patients on their decision about its use. To provide more evidence in this area, this study aims to evaluate the efficacy of Black cohosh on early menopausal symptoms using an RCT.

\section{Methods}

\section{Design}

This study was a randomized, double-blind, placebocontrolled trial. A total of 84 menopausal women were randomly allocated into treatment and control groups based on a block randomization with block sizes of 4 and 6 and an allocation ratio of 1:1. The allocation sequence was identified by computerized random numbers. Sequentially numbered sealed envelopes of the same shape and size containing Black cohosh or placebo tablets were used to conceal the allocation and to maintain the blinding. Every envelope contained 56 pills of Black cohosh or placebo. The participants were instructed to take one tablet per day after dinner for 8 weeks.

The envelopes were prepared by a person who was not involved in the recruitment, data collection, or data analysis. Therefore, the researchers and participants were unaware of the kind of tablets given to each participant (blinding).

The Black cohosh tablets, which were bought from a pharmacy, were in the form of coated tablets. Each tablet contained $6.5 \mathrm{mg}$ of dried extract of Black cohosh root, representing $0.12-0.18 \mathrm{mg}$ of 27 -deoxyactein. The tablets, named Cimifugol, are commercially distributed by Goldaroo Drug Company in Iran [31]. The placebo tablets were produced in the School of Pharmacy of Tabriz University of Medical Sciences. These tablets were the same as the Black cohosh tablets in shape, color, and size, and were thus indistinguishable from the Black cohosh tablets.

\section{Setting and participants}

Women who met the following criteria were eligible for recruitment: (1) age of 45-60 years; (2) no menstrual cycle in the last 12 months; and (3) GCS score of 15-42. The exclusion criteria included: (1) high blood pressure (more than 140/90 mmHg); (2) history of breast cancer, uterine cancer, abnormal vaginal bleeding, liver disease, depression, hypertension, or hyperthyroidism; (3) use of steroids or herbal medications for treatment of menopausal symptoms or psychiatric drugs within the last 2 months; (4) sensitivity to spices or essences; (5) smoking; and (6) alcohol consumption.

The subjects were selected from women referred to two public health care centers affiliated to Beheshti University of Medical Sciences, Tehran, Iran. These centers had the highest numbers of clients for family planning services among the centers affiliated to the university. All participants had household records at the centers for receipt of primary health care, including family planning services, in previous years and had reached the age of menopause. To contact the participants, we found their phone numbers from the records. Some of the eligibility criteria were checked over the phone. The potentially eligible subjects were invited to attend the centers. At the centers, the women were further informed about the study, the eligibility criteria were checked precisely, and informed consent forms were signed by the eligible women.

The research protocol were approved (Code 9061) by the Ethics Committee of Tabriz University of Medical Sciences and registered at the Iranian Registry of Clinical Trials with IRCT201107186709N4 on 15 January 2012 (http://www.irct.ir/searchresult.php?id=6709\&number=4). 
Table 1 Demographic characteristics of the study participants in the treatment (Black cohosh) and control (placebo) groups

\begin{tabular}{|c|c|c|c|}
\hline Variables & $\begin{array}{l}\text { Treatment } \\
\quad(n=42) \\
\text { Mean } \pm \text { SD }\end{array}$ & $\begin{array}{c}\text { Control } \\
(n=42) \\
\text { Mean } \pm \text { SD }\end{array}$ & Statistical results \\
\hline Age (years) & $51.4 \pm 4$ & $51.7 \pm 4.2$ & $\mathrm{t}=0.78, \mathrm{df}=82, P=0.43$ \\
\hline Length of menopause (months) & $35.1 \pm 20.6$ & $31.4 \pm 21.3$ & $\mathrm{t}=0.82, \mathrm{df}=82, P=0.41$ \\
\hline Systolic blood pressure $(\mathrm{mmHg})$ & $115.7 \pm 13.5$ & $115.2 \pm 8.6$ & $\mathrm{t}=0.19, \mathrm{df}=82, P=0.84$ \\
\hline Diastolic blood pressure $(\mathrm{mmHg})$ & $79.2 \pm 6.7$ & $77.3 \pm 6.6$ & $\mathrm{t}=1.30, \mathrm{df}=82, P=0.19$ \\
\hline \multirow[t]{2}{*}{ Body mass index $\left(\mathrm{kg} / \mathrm{m}^{2}\right)$} & $27.6 \pm 3.6$ & $26.3 \pm 2.9$ & $\mathrm{t}=1.83, \mathrm{df}=82, P=0.07$ \\
\hline & n (\%) & n (\%) & \\
\hline \multicolumn{4}{|l|}{ Education } \\
\hline Elementary & $9(21)$ & $6(14)$ & $x^{2}=4.49$ \\
\hline Secondary & $4(9)$ & $11(26)$ & $d f=3$ \\
\hline High school & $20(47)$ & $19(45)$ & $P=0.21$ \\
\hline Academic & $9(21)$ & $6(14)$ & \\
\hline \multicolumn{4}{|l|}{ Employment } \\
\hline Housewife & $33(78)$ & $33(78)$ & $x^{2}=0.22$ \\
\hline Employed & $4(9)$ & $5(11)$ & $\mathrm{df}=2$ \\
\hline Retired & $5(11)$ & $4(9)$ & $P=0.89$ \\
\hline \multicolumn{4}{|l|}{ Income adequacy } \\
\hline Yes & $15(35)$ & $14(33)$ & $x^{2}=0.17$ \\
\hline To some extent & $24(57)$ & $24(57)$ & $\mathrm{df}=2$ \\
\hline No & $3(7)$ & $4(9)$ & $P=0.91$ \\
\hline \multicolumn{4}{|l|}{ Exercise } \\
\hline Never & $7(17)$ & $10(24)$ & $x^{2}=0.71$ \\
\hline Sometimes & $15(36)$ & $13(31)$ & $d f=3$ \\
\hline Often & $13(31)$ & $12(28)$ & $P=0.87$ \\
\hline Always & $7(17)$ & $7(17)$ & \\
\hline \multicolumn{4}{|l|}{ Marital status } \\
\hline Married & $40(95)$ & $36(86)$ & $x^{2}=3.54$ \\
\hline Single & $1(2)$ & $2(4)$ & $d f=3$ \\
\hline Divorced & $1(2)$ & $1(2)$ & $P=0.31$ \\
\hline Widowed & $0(0)$ & $3(3)$ & \\
\hline
\end{tabular}

The sample size was calculated using STATA software version 9.2 (Statasoft Inc., USA) based on a study by Hakimi et al. [32]. Considering 28.1 as the mean and 1.98 as the standard deviation for the GCS score in the control group, a reduction in the GCS total score of at least $15 \%$ by the treatment, a one-sided significance level of 0.05 , a power of 0.80 , and a $10 \%$ probable drop in the sample, the required sample size was calculated to be 42 participants per group.

\section{Outcomes}

The primary outcome was the GCS total score assessed at weeks 4 and 8 of follow-up and the secondary outcomes were the GCS subscale scores (vasomotor, physical, psychiatric, and sexual symptoms) at the follow-ups as well as also possible side effects.

\section{Data collection}

Data were collected at baseline prior to the treatment, and also at weeks 4 and 8 after commencement of the treatment using a questionnaire. The questionnaire included demographic and GCS statements [30], which were completed in face-to-face interviews by the participants at the visits. The participants were also given a form, and were requested to mark their taking of the pills and the occurrence of any side effects (e.g., headaches, dizziness, 
Table 2 Comparisons of the treatment (Black cohosh) and control (placebo) groups in terms of the Greene climacteric scale total and subscale scores at baseline and two follow-up time-points

\begin{tabular}{|c|c|c|c|c|c|}
\hline \multirow[t]{2}{*}{ Outcome variables } & \multirow{2}{*}{$\begin{array}{c}\text { Treatment } \\
(\mathrm{n}=42) \text { Mean } \pm \text { SD }\end{array}$} & \multirow{2}{*}{$\begin{array}{c}\text { Control } \\
(n=42) \text { Mean } \pm \text { SD }\end{array}$} & \multicolumn{3}{|c|}{ Comparison of the groups } \\
\hline & & & Adjusted MD (95\% CI) & $P$ & Partial Eta ${ }^{2}$ \\
\hline \multicolumn{6}{|l|}{ Total score (0-63) } \\
\hline Baseline & $33.8 \pm 6.4$ & $31.1 \pm 6.3$ & $2.7(-0.1$ to 5.4$)$ & 0.059 & \\
\hline 4 weeks & $16.7 \pm 7.7$ & $22.9 \pm 9.2$ & $-7.8(-11.1$ to -4.4$)$ & $<0.001$ & 0.21 \\
\hline 8 weeks & $8.0 \pm 5.5$ & $19.5 \pm 11.0$ & $-12.9(-16.2$ to -9.3$)$ & $<0.001$ & 0.39 \\
\hline \multicolumn{6}{|c|}{ Vasomotor symptoms (0-6) } \\
\hline Baseline & $4.0 \pm 1.7$ & $3.5 \pm 1.6$ & 0.5 (-2.9 to 1.2$)$ & 0.22 & \\
\hline 4 weeks & $1.8 \pm 2.0$ & $2.6 \pm 1.7$ & $-1.1(-0.4$ to -1.8$)$ & 0.002 & 0.11 \\
\hline 8 weeks & $0.7 \pm 1.6$ & $2.4 \pm 1.8$ & $-1.9(-1.2$ to -2.6$)$ & $<0.001$ & 0.26 \\
\hline \multicolumn{6}{|c|}{ Psychiatric symptoms (0-33) } \\
\hline Baseline & $18.8 \pm 4.8$ & $18.8 \pm 4.3$ & $0.1(-2.1$ to 1.9$)$ & 0.92 & \\
\hline 4 weeks & $10.8 \pm 5.0$ & $13.3 \pm 6.4$ & $-2.6(-0.3$ to -4.9$)$ & $<0.001$ & 0.16 \\
\hline 8 weeks & $4.2 \pm 3.5$ & $11.4 \pm 7.4$ & $-7.3(-9.6$ to -5.0$)$ & $<0.001$ & 0.31 \\
\hline \multicolumn{6}{|c|}{ Physical symptoms (0-21) } \\
\hline Baseline & $7.7 \pm 3.5$ & $6.6 \pm 2.7$ & $1.1(-0.3$ to 2,5$)$ & 0.10 & \\
\hline 4 weeks & $3.1 \pm 2.3$ & $4.7 \pm 2.8$ & $-2.0(-3.1$ to -1.0$)$ & $<0.001$ & 0.06 \\
\hline 8 weeks & $1.4 \pm 1.5$ & $3.7 \pm 2.4$ & $-2.5(-3.3$ to -1.7$)$ & $<0.001$ & 0.33 \\
\hline \multicolumn{6}{|c|}{ Loss of interest in sex (0-3) } \\
\hline Baseline & $2.6 \pm 0.8$ & $2.4 \pm 1.4$ & $0.2(-0.7$ to 0.3$)$ & 0.47 & \\
\hline 4 weeks & $1.8 \pm 1.0$ & $1.9 \pm 1.0$ & $-0.37(-0.72$ to -0.03$)$ & 0.03 & 0.06 \\
\hline 8 weeks & $1.6 \pm 1.1$ & $1.9 \pm 1.0$ & $-0.52(-0.89$ to -0.15$)$ & 0.006 & 0.09 \\
\hline
\end{tabular}

nausea, and vomiting) on the form every day and return it to the researcher at the next visit. Furthermore, we checked the treatment compliance and possible side effects over the phone once a week.

The GCS scale consisted of 21 statements. Eleven statements pertained to psychiatric symptoms, and included two parts, anxiety and depression. Seven statements assessed physical aspects and two assessed vasomotor symptoms. The final statement considered sexual desire disorder. The severity of the symptoms was scored as zero (no symptoms), one (mild), two (moderate), and three (severe) based on self-reporting [30]. To determine the reliability, a test-retest was used $(r=0.96)$.

\section{Statistical analysis}

The normality of the quantitative variables for each of the groups was confirmed using the Kolmogorov-Smirnov test. An independent $t$-test was used for comparison of the baseline scores, and a general linear model with repeated measures was used for comparison of the followup scores adjusted for the baseline values, time, and interaction between time and group. The Greenhouse-Geisser test was used to determine the interaction effect. A partial $\mathrm{Eta}^{2}$ value was recorded for the effect size of the treatment and the interaction. All data analyses were carried out using SPSS for Windows 13.0 (SPSS Inc., USA). Values of $P<0.05$ were considered to indicate statistical significance.

\section{Results}

There was no loss to follow-up and all participants continued the study to the end. Both groups were similar in terms of the personal and societal characteristics (Table 1). The average age in both groups was approximately 51 years. The majority of patients in both groups had high school education or above, and were married housewives. Overall, $17 \%$ of women in the treatment group and $24 \%$ in the control group did no exercise at all.

At baseline, the mean \pm standard deviation of the GCS total score was $33.8 \pm 6.4$ in the treatment group and $31.1 \pm 6.4$ in the control group, with no significant difference. In addition, the groups had similar scores for all GCS subscales (Table 2).

The GCS total score in the treatment group was significantly lower than that in the control group at both week 4 [adjusted mean difference: -7.8 (95\% confidence interval: -11.1 to -4.4$), P<0.001]$ and week $8[-12.9$ ( -16.2 to -9.3$), P<0.001]$. The treatment group also showed significantly more improvement than the control group in all GCS subscale scores (vasomotor, psychiatric, physical, and sexual symptoms). 


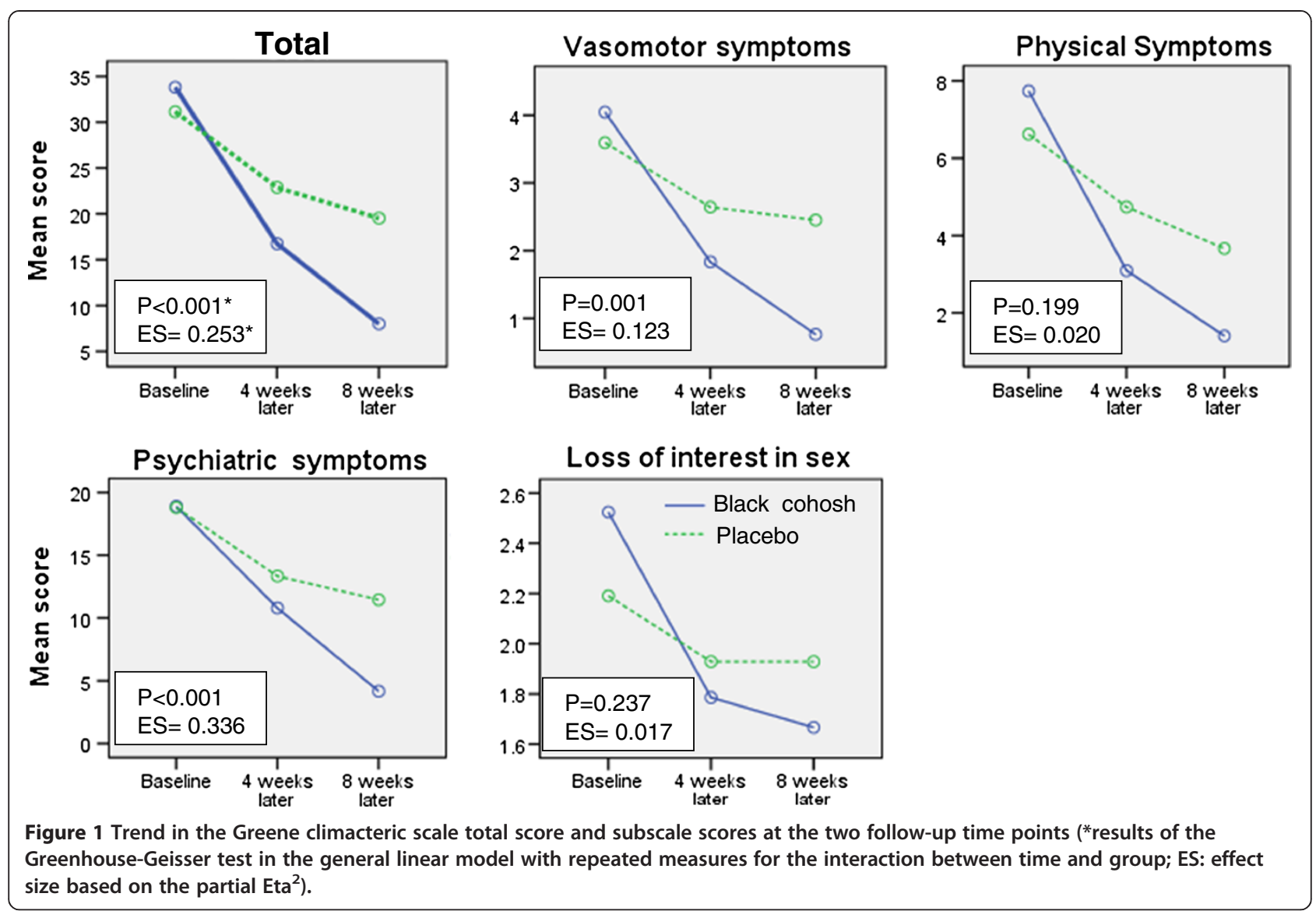

At weeks 4 and 8 , there were $51 \%$ and $77 \%$ reductions in the GCS total score (relative effect) in the treatment group compared with $27 \%$ and $38 \%$ in the control group, respectively. Reductions in the vasomotor symptom score of $61 \%$ and $86 \%$ were observed in the treatment group compared with $27 \%$ and $29 \%$ in the control group. The reductions in the psychiatric symptom score were $46 \%$ and $79 \%$ in the treatment group compared with $31 \%$ and $42 \%$ in the control group. The reductions in the physical symptom score were $63 \%$ and $82 \%$ in the treatment group compared with $27 \%$ and $42 \%$ in the control group. The reduction in the loss of interest in sex score were $29 \%$ and $36 \%$ in the treatment group compared with $8 \%$ and $10 \%$ in the control group. The effect size was considerable (partial Eta ${ }^{2}:>0.3$ ) in terms of the total, physical, and psychiatric symptoms at 8 weeks of follow-up (Table 2).

The differences between the treatment and control groups at week 8 were significantly higher than those at week 4 in terms of the total score $(P<0.001)$ and vasomotor $(P=0.001)$ and psychiatric $(P<0.001)$ subscale scores. In the other two subscales, physical and sexual symptoms, the effects were higher at week 8 , but the differences were not significant compared with week 4
( $P=0.199$ and $P=0.237$, respectively) (Figure 1 ). No side effects were reported in either of the groups.

\section{Discussion}

Intake of Black cohosh $(6.5 \mathrm{mg}$ of dried extract of the roots of the plant) for 8 weeks, comprising one tablet every night after dinner, reduced the symptoms in early post-menopausal women compared with intake of placebo. The treatment efficacy increased with longer use.

The results of this study are consistent with the results of some previous studies comparing the effects of daily intake of $6.5 \mathrm{mg}$ of dried rhizome extract of Black cohosh [21] or $40 \mathrm{mg}$ of herbal drug Black cohosh with peri- and post-menopausal women [22,23] on reducing climacteric complaints compared with intake of placebo, and the women in the early climacteric phase benefited more than those in the late phase [22].

The effects of Black cohosh on reducing climacteric symptoms in peri- and post-menopausal women were similar to those of other effective treatment methods like conjugated estrogens [23] and tibolone [33], and even higher than those of fluoxetine [34].

The present results appear inconsistent with the results of some other studies. Geller et al. [24] showed that the 
effect of Black cohosh $(64 \mathrm{mg} /$ day $)$ in reducing the number of vasomotor symptoms was not significantly different from that of placebo and was significantly lower than $0.625 \mathrm{mg}$ of conjugated equine estrogens plus $2.5 \mathrm{mg}$ medroxyprogesterone acetate. The difference may be related to the longer interval between the initiation of treatment and the outcome assessment, since the study outcome was assessed at 12 months after initiation of the treatment compared with 2 months in our study. Jacobson et al. [35] demonstrated that Black cohosh was not significantly effective in reducing most postmenopausal symptoms. However, all participants in their study had breast cancer and most (70\%) were taking tamoxifen. Higher loss of follow-up (20\%) may also have affected the results. Amsterdam et al. [25] demonstrated that Black cohosh did not significantly reduce the GCS scores in peri- and post-menopausal women. This inconsistency with our results may be related to the small sample size (only 28), relatively higher loss to follow-up (25\%), or choice of Black cohosh preparation and dosage. No adverse side effects were seen in our Black cohosh users, consistent with the results of other studies $[22,23,25,33,34]$.

The double-blinding and no loss to follow-up were important strengths of this study. The duration of the treatment in this study was relatively short (8 weeks) and we did not have any follow-up after ceasing Black cohosh use because of time and financial limitations. Although the GCS score is a subjective outcome (selfreporting), the results may not be affected by subjectivity because of the double blinding of the study. Other outcomes like urogenital and ophthalmic symptoms, follicle-stimulating hormone serum levels, and bone metabolism were not assessed, and safety was only assessed by self-reporting because of financial limitations. In addition, the effect of Black cohosh was not compared with a standard treatment, i.e., hormone replacement therapy based on the results.

\section{Conclusions}

Black cohosh reduced the GCS total score and all GCS subscale scores (vasomotor, psychiatric, physical, and sexual symptoms) during 4 and 8 weeks of treatment.

\section{Abbreviations}

IRCT: Iranian registry of clinical trials; GCS: Greene climacteric scale; RCT: Randomized controlled trial.

\section{Competing interests}

The authors declare that they have no competing interests.

\section{Authors' contributions}

SMAC and MS designed and supervised the study, and performed the statistical analyses. JN wrote the manuscript and conducted the experiments. SB assisted experimentally. All authors read and approved the final version of the manuscript.

\section{Acknowledgments}

This article is extracted from an MSc thesis in midwifery and its research project was approved by the Tabriz University of Medical Sciences with No. 5/55/7304 dated 07 February 2012. We thank all the participants in this research. We also wish to thank the people in charge of the Nursing and Midwifery College and the Research Deputy of Tabriz University of Medical Sciences for financial assistance, the people in charge of Sardar Jangal and Shahid Ghaffari Health and Treatment Centers and the Research Deputy of Shahid Beheshti University of Medical Sciences, and all other colleagues who helped us in conducting this research.

Received: 11 May 2013 Accepted: 23 October 2013

Published: 1 November 2013

\section{References}

1. The North American Menopause Society: Menopause Practice: A Clinician's Guide 4th edition. Ohio: NA MENOP; 2010

2. Shifren JL: Menopause. In Berek and Novak's Gynecology. 14th edition. Edited by Berek JS. Philadelphia: Lippincott Williams and Wilkins; 2007:1323-1339.

3. Low Dog T, Riley D, Carter T: An integrative approach to menopause. Altern ther Health Med 2001, 7:45-55.

4. Impey L, Child T: Obstetrics and Gynecology. Oxford: Blackwell Science; 1999

5. Blumel JE, Castelo-Branco C, Binfa L, Gramegna G, Tacla X, Aracena B, Cumsille MA, Sanjuan A: Quality of life after the menopause: a population study. Maturitas 2000, 34:17-23.

6. Shohani M, Rasouli F, Hagiamiri P, Mahmoudi M: The survey of physical and mental problems of menopause women referred to llam health care centers. Iranian Journal of Nursing Research 2007, 2:57-65. Persian.

7. Maclennan AH, Broadbent JL, Lester S, Moore V: Oral oestrogen and combined oestrogen/progestogen therapy versus placebo for hot flushes. Cochrane Database Syst Rev 2004(4). Art. No.: CD002978. DOI: 10.1002/14651858.CD002978.pub2.

8. Rossouw JE, Anderson GL, Prentice RL, LaCroix AZ, Kooperberg C, Stefanick ML, Jackson RD, Beresford SA, Howard BV, Johnson KC, Kotchen JM, Ockene J, Writing Group for the Women's Health Initiative Investigators: Risks and benefits of estrogen plus progestin in healthy postmenopausal women: principal results from the Women's Health Initiative randomized controlled trial. JAMA 2002, 288:321-333.

9. Ettinger B, Grady D, Tosteson AN, Pressman A, Macer JL: Effect of the Women's Health Initiative on women's decisions to discontinue postmenopausal hormone therapy. Obstet Gynecol 2003, 102:1225-1232.

10. Bashiri A: Assessing reasons of using or not using replace therapy in menopausal women in Tehran. MSc Thesis. Tehran: Tehran University of Medical Sciences, Midwifery Department; 2001. Persian.

11. Manson JE, Hsia J, Johnson KC, Rossouw JE, Assaf AR, Lasser NL, Trevisan M, Black HR, Heckbert SR, Detrano R, Strickland OL, Wong ND, Crouse JR, Stein E, Cushman M, Women's Health Initiative Investigators: Estrogen plus progestin and the risk of coronary heart disease. N Eng J Med 2003, 349:523-534.

12. Grady D, Yaffe K, Kristof M, Lin F, Richards C, Barrett-Connor E: Effect of postmenopausal hormone therapy on cognitive function: the Heart and Estrogen/progestin Replacement Study. Am J Med 2002, 113:543-548.

13. Timbo BB, Ross MP, McCarthy PV, Lin CT: Dietary supplements in a national survey: Prevalence of use and reports of adverse events. J Am Diet Assoc 2006, 106:1966-1974.

14. Russell L, Hicks GS, Low AK, Shepherd JM, Brown CA: Phytoestrogens: a viable option? Am J Med Sci 2002, 32:185-188.

15. Barnes J, Anderson LA, Phillipson D: Herbal medicines. 3rd edition. London: PHP; 2007.

16. Gruenwald J, Brendler TH, Jaenicke CH: PDR for herbal medicines. 4th edition. Thomson health care, Inc: Montvale; 2008.

17. Burdette JE, Liu J, Chen SN, Fabricant DS, Piersen CE, Barker EL, Pezzuto JM, Mesecar A, Van Breemen RB, Farnsworth NR, Bolton JL: Black cohosh acts as a mixed competitive ligand and partial agonist of the serotonin receptor. J Agric Food Chem 2003, 51:5661-5670.

18. Liao JF, Jan YM, Huang SY, Wang HH, Yu LL, Chen CF: Evaluation with receptor binding assay on the water extracts of ten CNS-active Chinese herbal drugs. Proc Natl Sci Counc Repub China B 1995, 19:151-158.

19. Reame NE, Lukacs JL, Padmanabhan V, Eyvazzadeh AD, Smith YR, Zubieta JK: Black cohosh has central opioid activity in postmenopausal women: evidence from naloxone blockade and positron emission tomography neuroimaging. Menopause 2008, 15:852-840. 
20. Blumental M: The complete German commission E monographs. American botanical council: Texas; 1998.

21. Frei-Kleiner S, Schaffner W, Rahlfs WW, Bodmer C, Birkhauser M: Cimicifuga racemosa dried ethanolic extract in menopausal disorders: a double-blind placebo-controlled clinical trial. Maturitas 2005, 51:397-404.

22. Osmer R, Friede M, Liske E, Schnitker J, Freudenstein J, Henneicke-Von Zepelin HH: Efficacy and safety of isopropanolic black cohosh extract for climacteric symptoms. Obestet Gynecol 2005, 105:1074-1083.

23. Wuttke W, Seidlova-Wuttke D, Gorkow C: The Cimicifuga preparation BNO 1055 vs. conjugated estrogens in a double-blind placebo-controlled study: effects on menopause symptoms and bone markers. Maturitas 2003, 44:567-s77.

24. Geller SE, Shulman LP, van Breemen RB, Banuvar S, Zhou Y, Epstein G, Hedayat S, Nikolic D, Krause EC, Piersen CE, Bolton JL, Pauli GF, Farnsworth NR: Safety and efficacy of black cohosh and red clover for the management of vasomotor symptoms. Menopause 2009, 16:1156-1166.

25. Amesterdam JD, Yao Y, Mao JJ, Soeller I, Rockwell K, Shults J: Randomized, double-blind, placebo-controlled trial of Cimicifugaracemosa (black cohosh) in women with anxiety disorder due to menopause. J Clin Psycopharmacol 2009, 29:478-483.

26. Borrelli F, Ernst E: Black cohosh (Cimifugaracemosa) for menopausal symptoms: a systematic review of its efficacy. Pharmacol Res 2008, 58:8-14.

27. Leach MJ, Moore V: Black cohosh (Cimicifuga spp.) for menopausal symptoms. Cochrane Database Syst Rev 2012(9). Art. No.: CD007244. DOI: 10.1002/14651858.CD007244.pub2.

28. Hicky M, Davis SR, Sturdee DW: Threatment of menopausal symptoms: What shall we do now? Lancet 2005, 366:409-421.

29. Mahady GB: Black cohosh (Actaea/Cimicifugaracemosa): review of the clinical data for safety and efficacy in menopausal symptoms. Treat Endocrinol 2005, 4:177-184.

30. Greene JG: Constructing a standard climacteric scale. Maturitas 1998 , 29:25-31.

31. Goldaru Company: Pharmacopoeia of herbal medicines Flower. In Drugs with accreditation from the Ministry of Health and Medical Education. Esfahan: Pooyeshe Andish; 2010:48. Persian.

32. Hakimi S, Mohamadalizadeh Charandabi S, Siahi MR, Bamdadmogadam R, Abasalizade F, Garebaghi PM: Effect of Fenugreek seed on early menopausal symptoms. Pharmaceutical Sciences 2005, 10(2):83-90. Persian.

33. Bai W, Henneicke-von Zepelin HH, Wang S, Zheng S, Liu J, Zhang Z, Geng L, Hu L, Jiao C, Liske E: Efficacy and tolerability of a medicinal product containing an isopropanolic black cohosh extract in Chinese women with menopausal symptoms: a randomized, double blind, parallel-controlled study versus tibolone. Maturitas 2007, 58:31-41.

34. Oktem M, Eroglu D, Karahan HB, Taskintuna N, Kuscu E, Zeyneloglu HB: Black cohosh and fluoxetine in the treatment of postmenopausal symptoms: a prospective, randomized trial. Adv Ther 2007, 24:448-461

35. Jacobson JS, Troxel AB, Evans J, Klaus L, Vahdat L, Kinne D, Steve Lo KM, Moore A, Rosenman PJ, Kaufman EL, Neugut Al, Grann VR: Randomized trial of black cohosh for the treatment of hot flashes among women with a history of breast cancer. J Clin Oncol 2001, 19:2739-2745.

doi:10.1186/1749-8546-8-20

Cite this article as: Mohammad-Alizadeh-Charandabi et al.: Efficacy of black cohosh (Cimicifuga racemosa L.) in treating early symptoms of menopause: a randomized clinical trial. Chinese Medicine 2013 8:20,

\section{Submit your next manuscript to BioMed Central and take full advantage of:}

- Convenient online submission

- Thorough peer review

- No space constraints or color figure charges

- Immediate publication on acceptance

- Inclusion in PubMed, CAS, Scopus and Google Scholar

- Research which is freely available for redistribution

Submit your manuscript at www.biomedcentral.com/submit
C Biomed Central 